\title{
The Afterlife of Drugs and the Role of PharmEcovigilance
}

\author{
Christian G. Daughton, $\mathrm{PhD}$ \\ Chief, Environmental Chemistry Branch \\ National Exposure Research Laboratory \\ US Environmental Protection Agency \\ 944 East Harmon Avenue \\ Las Vegas, Nevada 89119 \\ Ilene Sue Ruhoy, MD \\ Assistant Professor, Basic and Clinical Sciences \\ Touro University Nevada \\ College of Osteopathic Medicine \\ Henderson, NV 89014
}

Running Title: Afterlife of Drugs and Role of PharmEcovigilance

REVISED 4 July 2008

Preprint:

Daughton CG and Ruhoy IS "The Afterlife of Drugs and the Role of

PharmEcovigilance," Drug Safety, 2008, 31(12):1069-1082; available: http://

dx.doi.org/10.2165/0002018-200831120-00004 
Acknowledgments: ISR thanks David Hassenzahl, University of Nevada, Las Vegas for continued guidance, and the U.S. Environmental Protection Agency for granting an appointment as a U.S. EPA Student Volunteer.

US EPA Notice: The United States Environmental Protection Agency through its Office of Research and Development funded and managed the research described here. It has been subjected to the Agency's administrative review and approved for publication as an EPA document. 
Corresponding Author:

Christian G. Daughton, PhD

Chief, Environmental Chemistry Branch

National Exposure Research Laboratory

US Environmental Protection Agency

944 East Harmon Avenue

Las Vegas, Nevada 89119

702-798-2207

702-798-2142 (fax)

daughton.christian@epa.gov 


\title{
Table of Contents:
}

\author{
Abstract \\ Background \\ The Lifecycle of a Drug: \\ The Roles of Pharmacovigilance and PharmEcovigilance: \\ Potential Consequences of Ecological Exposure to APIs: \\ Concerns Regarding Human Exposure to APIs from the Environment \\ Role of the Physician and other Prescribers \\ Conclusion \\ References \\ Tables I-IV \\ Figure 1 \\ Figure 2
}




\section{Figure Captions:}

Figure 1. Unanticipated Exposure to API Residues from the Environment

Figure 2. Role of PharmEcovigilance in Minimizing Human \& Ecological Impacts of APIs 


\section{ABSTRACT}

2 The prescribing and usage of medications (for both humans and domestic animals) have ramifications extending far beyond the traditional objectives of conventional medical care. The

4 healthcare industry has an environmental footprint that includes the active pharmaceutical ingredients (APIs) from medications, residues of which can establish themselves as

6 environmental pollutants. This occurs by a variety of routes, but primarily from excretion, bathing, and disposal. Many parallels exist between healthcare and the protection and

8 remediation of the environment, spanning the stages from symptomology and diagnosis to treatment. The critical role played by pharmacovigilance in healthcare has a counterpart with the

10 ecological environment. The term ecopharmacovigilance has been used with respect to the unforeseen consequences APIs can have once they enter the environment. We propose that

12 conventional pharmacovigilance could be expanded to encompass environmental concerns - a concept we term pharmEcovigilance - as a way to unify the parallel but interconnected needs

14 for protecting both human and ecological health.

16 To convey the scope of a pharmEcovigilance program, we provide an overview of the occurrence of APIs as environmental pollutants, their ramifications for human health and the 18 environment, and some of the ways in which their impact could be reduced or minimized. The major areas discussed include: (i) the routes by which APIs become contaminants in the

20 environment, (ii) the hazards of leftover drugs as a result of stockpiling and from disposal to sewerage, which can also eventually contribute to the contamination of drinking water, (iii) why

22 drugs accumulate unused, and (iv) the benefits for humans and the environment that could accrue 
from reducing the accumulation of leftover drugs and the subsequent introduction of APIs to the

2 environment.

4 A broad spectrum of actions could be taken by prescribers (including veterinarians) and the healthcare industry at large (including manufacturers and insurers) to reduce the release or

6 introduction of APIs to the environment. Most significantly, however, a major reason to consider implementing a pharmEcovigilance program — beyond reducing the environmental

8 footprint of healthcare - is the previously unforeseen collateral benefits in making further progress in optimizing the delivery, effectiveness, outcomes, and cost of healthcare, as well as 10 improving safety for humans, pets, and wildlife.

12 For this reason, the relationships that healthcare professionals and patients have with medications might also include consideration of pharmEcovigilance. Like any profession that deals with

14 chemicals, perhaps a major challenge to be faced is how to ensure the sustainability (and minimize the lifecycle exposure hazards) of a chemical-based, chemical-centric society in the

16 most cost-effective and safest manner. Given that the medical community is a major source of numerous "exotic" chemical pollutants in the environment (with thousands of chemically distinct

18 APIs in current use) — albeit at very low levels — an imperative could be created for designing and implementing approaches for reducing and controlling this source of pollution. With reduced

20 wastage of medications, in part driven by appropriate or rational prescribing and dispensing, the ecological footprint of medicine could be greatly reduced, with concomitant improvements in 22 many aspects of healthcare. 


\section{BACKGROUND}

4 During medical training, student doctors learn the importance of evaluating an individual patient before deciding which medication to choose for treatment or whether to prescribe a drug at all.

6 The pharmacological education in most medical schools emphasizes the negative health consequences for the patient from inappropriate, or inadvertent, exposure to prescribed

8 pharmaceuticals, and physicians are trained to investigate potential adverse effects or inappropriate consumption by their patients. But the reality is that another type of human

10 exposure to medication ingredients may be occurring routinely, albeit at extremely small doses. Unbeknownst to most physicians, all who prescribe play a large, however unintentional, role in

12 the exposure of the public to the active ingredients in medications because these bioactive chemicals are continually introduced or released to the environment as a result of their intended

14 and purposeful use. The most significant exposures occur for aquatic organisms (because the concentrations are higher than exist in drinking water and because they are exposed for longer

16 durations - sometimes on a continual basis). However, it is currently unknown to what extent humans are exposed to these trace residues that are recycled from the environment in drinking

18 water. Nor do we know the potential for additive, synergistic, antagonistic, or unexpected effects from simultaneous trace exposure to multiple ingredients. While a broad spectrum of pollution

20 prevention and stewardship approaches exists for minimizing the subsequent exposures of the public and the environment, they are just beginning to be considered. Many of these approaches

22 fall under the purview of physician responsibility with regard to prescribing and treatment management practices; others reside within the purview of those who oversee or influence

24 dispensing, insurance companies being one example. Physicians have a variety of opportunities to play a major role in this public health dilemma. Note that in this work, the term "physician" is 
often used in a very broad, general context to include other professions that can prescribe

2 (although usually to more limited extents), including veterinarians, dentists, nurse practitioners, physician assistants, and even pharmacists.

4

In this paper we discuss the occurrence of active pharmaceutical ingredients (APIs) as

6 environmental pollutants, their ramifications for human health and the environment, and some of the ways in which their impact could be reduced or minimized. The major areas discussed

8 include: (i) the routes by which APIs become contaminants in the environment, (ii) the hazards of leftover drugs as a result of stockpiling and from disposal to sewage, which can also

10 eventually contribute to the contamination of drinking water, (iii) why drugs accumulate unused, and (iv) the benefits for humans and the environment that could accrue from reducing the

12 accumulation of leftover drugs and the subsequent introduction of APIs to the environment. We also introduce the concept of pharmEcovigilance as a way to unify the parallel but interrelated

14 needs for protecting both human and ecological health.

\section{The Lifecycle of a Drug}

Humans impart unique chemical signatures on the environment in the form of minute residues of

18 pharmaceuticals that we excrete, wash from our bodies, or discard to sewerage or trash. While the minuscule contributions from each individual may be insignificant by themselves, the

20 collective contributions from all individuals can reach measurable levels in surface and ground waters and on land receiving treated sewage. After release to the environment, the lifecycle of

22 APIs continues with biological exposures for the environment and humans (see Figure 1). Some 
of the unique aspects and consequences of this extended life are summarized in Table I and

2 Table II, respectively.

4 Active pharmaceutical ingredients occur in the ambient environment at concentrations that not long ago were considered infinitesimally low (especially when compared with common

6 therapeutic doses, which are often in the $\mathrm{mg} / \mathrm{kg}$ range). Concentrations in water or foods generally range from parts-per-billion $(\mu \mathrm{g} / \mathrm{L}$ or $\mu \mathrm{g} / \mathrm{kg}$ ) to sub-parts-per-trillion (ppt) (sub-ng/L or

$8 \mathrm{ng} / \mathrm{kg}$, or picomolar) and lower. That APIs are widespread environmental pollutants has been well established in an ever-growing body of published literature (see literature database ${ }^{[8]}$

10 maintained by the U.S. EPA) $\cdot{ }^{[9,10]}$ Worth noting, however, is that while there are thousands of distinct APIs in commercial use, all of which are capable of eliciting a broad spectrum of unique

12 biological effects, chemists have sought to identify only a small fraction of them in environmental samples. So the true extent and magnitude of contamination of the environment

14 by APIs has been only partly delineated.

16 The APIs in medications that are prescribed and dispensed enter the environment by two major routes. First, excess medications find their way into the environment when consumers dispose of 18 unwanted leftover stocks, especially into sewers (e.g., flushing down toilets or grinding in garbage disposals). Second, APIs enter the environment as a result of their intended use — as a

20 result of excretion of APIs not fully metabolized and as a result of washing away topically applied medications during bathing. Worth noting are several additional aspects to these routes

22 rarely ever discussed. First, while disposal primarily concerns leftover unused medications, partially used medications (especially delivery systems or devices) also serve as a source of APIs 
during disposal, as the remaining residuals can represent a significant portion of the amount

2 present in new, unused devices. Transdermal and transmucosal devices are two examples; after 3 days of use, for example, fentanyl patches are reported to retain $28-84 \%$ of their original fentanyl

4 content, more than sufficient for a lethal oral dose. ${ }^{[1]}$ Second, while most unmetabolized, parent APIs are excreted via feces and urine, measurable quantities can also be excreted via sweat and

6 can then be introduced to sewers during bathing (or can be transferred to other surfaces during bodily contact); this route of excretion has been investigated primarily for drugs of abuse (e.g.,

8 Barnes et al. ${ }^{[12]}$ ), such as for use in abuse monitoring by "sweat patch" testing, but the route is also known to pertain to therapeutic pharmaceuticals (e.g., Høiby et al. ${ }^{[13]}$ ). While the

10 concentrations of APIs in the aqueous environment are generally very low, ${ }^{[14,15]}$ usually less than $1 \mu \mathrm{g} / \mathrm{L}$, it is not known what the relative contributions are from excretion versus disposal. ${ }^{[16]}$

Many APIs are not fully removed by sewage treatment plants ${ }^{[15]}$ and are then discharged with the 14 treated sewage effluent into waterways. The release of untreated raw sewage by straightpiping or by overflow events, a growing problem in certain municipalities, serves to maximize the release

16 of APIs to waterways. Iodinated X-ray contrast media (which are used in very large quantities) and carbamazepine are examples of APIs that resist removal in sewage treatment plants. Even

18 for those APIs that have relatively short half-lives in the environment (those that are rapidly degraded by natural means such as biodegradation), their continual replenishment via sewage

20 leads to their constant presence — a phenomenon termed "pseudopersistence". ${ }^{[1]}$ Alternatively, APIs released into septic systems can leach into the groundwater (roughly one-quarter of the US

22 population is served by on-site septic systems). ${ }^{[18]}$ Contaminated surface and ground waters often serve as supplies for drinking water. APIs can therefore be unintentionally "recycled" back 
to humans in drinking water, providing ongoing, minute doses. ${ }^{[19]}$ This aspect of APIs as

2 pollutants garnered attention from a U.S. Senate subcommittee during a 2008 hearing on pharmaceuticals in drinking water. ${ }^{[20]}$

4

During sewage treatment, many APIs will associate with the sewage sludge, resulting in

6 concentrations much higher than in the treated waters. ${ }^{[21]}$ The API-contaminated sludge is often used (together with treated wastewater) to amend (and irrigate) agricultural croplands.

8 Agricultural food crops can sometimes absorb the APIs, ${ }^{[22]}$ posing the possibility of serving as a subsequent source for unintentional exposure for humans.

Reducing the initial introduction of pharmaceuticals into the environment, and thereby

12 diminishing the significance of the weaknesses in the treatment process, is an important, but complicated, focus of pollution prevention and source control. Leftover, unwanted medications

14 can also accumulate in a bewildering number of locations ${ }^{[2]}$ (also see illustration: Daughton ${ }^{[19]}$ ), far beyond the ubiquitous household medicine cabinet, from where they are often disposed into

16 toilets and trash. ${ }^{[16]}$ Physicians are very aware of many of the causes for leftover drugs that are not fully consumed and therefore accumulate. Patient non-compliance and alterations in

18 treatment regimens are two of the major reasons (Figure 1); this topic has been covered by Daughton and Ruhoy ${ }^{[23]}$ and Ruhoy and Daughton. ${ }^{[2]}$ Examining the life cycle of a medication

20 perhaps reveals the most important aspect of why we should care about trace levels of pharmaceuticals in the environment. To date, the focus of environmental scientists has tended to

22 dwell on establishing environmental occurrence and studying source control (waste and drinking water treatment) and the potential for aquatic effects. The actual origins of the problem have 
garnered significantly less scientific scrutiny, attention being focused instead on designing

2 stewardship approaches for dealing with unwanted, leftover medications. In the U.S., the first federal guidance for consumer disposal of unused drugs was issued in February of 2007 by the

4 White House Office of National Drug Control Policy. ${ }^{[24]}$ The US EPA has summarized the prudent disposal alternatives available in the US and is evaluating new alternatives. ${ }^{[25]}$ The

6 proper disposal of drugs is important for reducing the unnecessary entry of drugs to the environment (such as by flushing or disposal to trash), but even more so for reducing the very

8 real problem of human morbidity and mortality due to diversion of drugs from accumulated stockpiles awaiting disposal and consequent poisonings. Even partially used medications can

10 pose serious hazards. Used fentanyl patches are one example, where poisonings occur from their intentional reuse ${ }^{[7]}$ and from ingestion, such as by children. ${ }^{[6]}$ This is the major reason that

12 prompt and prudent disposal of leftover, unwanted drugs and partially used medications is so critical.

Beyond the proper disposal of unwanted drugs, the ultimate focus with regard to pollution

16 prevention should address the way in which drugs are prescribed and dispensed. The concept of the "Green Pharmacy" (which serves as a guide for continual improvement) would comprise a

18 comprehensive, holistic program whose objective would be to ensure that the types and quantities of medications used in the practice of medicine (and in self-medication) would

20 optimize the health of society as balanced against the well being of the environment; indeed, the need for balancing human and ecological health is noted by an EU directive: "An evaluation of

22 the positive therapeutic effects of the medicinal product in relation to the risks [associated with] undesirable effects on the environment". ${ }^{[26]}$ An efficient and widely implemented approach to a 
green pharmacy would strive to avoid the generation of leftover medications, resulting in

2 minimal waste requiring disposal. Humans and domestic animals would ideally receive exactly the treatment they needed, with minimal well-targeted doses that also minimized adverse effects.

4 APIs would be designed for extensive metabolism or environmental transformation to less-active products, and excreted residues would have minimal impact on the environment (e.g., minimal

6 potential to persist, bioconcentrate, or impart adverse effects on non-target organisms). Many suggestions have been suggested by Daughton under the concept of the green pharmacy. ${ }^{[27,28]}$

8 Approaches to minimize environmental impact using green chemistry (e.g., "benign by design") have been recently published by Kümmerer ${ }^{[29]}$ and Khetan and Collins ${ }^{[30]}$. Additional factors 10 may play roles (such as patient compliance and direct-to-consumer advertising, which is practiced only in the U.S. and New Zealand), which would also require attention. The end result

12 of a "greener" healthcare system would not just be a cleaner environment, but also more efficient usage of healthcare resources, reduced healthcare costs, improved healthcare outcomes, and

14 reduced incidence of purposeful abuse and accidental poisonings from diversion of stockpiled drugs. The health of humans and the environment is indeed intertwined, and there is a need for 16 their mutual care and attention.

\section{The Roles of Pharmacovigilance and PharmEcovigilance}

The medical, pharmaceutical, pharmacy, and regulatory communities have long tracked the

20 incidence of adverse effects of medications once they are in routine use. Formal programs are established for post-market surveillance — referred to as pharmacovigilance. 
Since the public at large can be exposed to APIs unknowingly, APIs clearly have a more

2 complex lifecycle - one where an expansion of the traditional role and scope of

pharmacovigilance might benefit all. We have recently coined the term pharmEcovigilance ${ }^{[31]}$

4 which considers the more wide-ranging implications of medication usage — adverse consequences for both humans and the environment. Just as most medications have the potential

6 for adverse or unintended effects on patients, they also have the potential for adverse effects on the environment and pose at least a perceived risk for the unsuspecting public (see Table I). The many unknowns involved with whatever risks might exist from exposure of humans or the environment to "recycled" APIs contribute to the debate surrounding the precautionary principle,

10 and specifically its impact on risk assessment with respect to pollution by APIs. This topic has been recently discussed by Enick and Moore. ${ }^{[32]}$ The concept of pharmEcovigilance incorporates

12 the many actions that physicians (among others, such as insurance companies, pharmacists, other prescribers, veterinarians, manufacturers, and consumers) can take to reduce the introduction or

14 release of APIs into the environment, as well as to lessen diversion. Since a major objective of pharmEcovigilance and its role in a green pharmacy would be to improve the overall quality of

16 healthcare, we believe that the precautionary principle does not need to be invoked in order to justify such a program.

Attention to the importance of adverse drug reactions (ADRs) was largely fostered by Meyler's

20 famous work ("Side Effects of Drugs"), first published in 1951 and now in its 15th edition. ${ }^{[33]}$ The World Health Organization (WHO) has played a central role in ADR reporting. Approaches

22 leading to the formalization of pharmacovigilance began in the 1970s, with adoption of a resolution by the World Health Assembly to explore the feasibility of an international system for 
monitoring ADRs, which led to WHO's Programme on International Drug Monitoring and the

2 WHO Uppsala Monitoring Centre, which maintains the international database of ADRs. A widely accepted definition of pharmacovigilance comes from the WHO: ${ }^{[34]}$ "... science and

4 activities relating to the detection, assessment, understanding and prevention of adverse effects or any other medicine-related problem."

6

Awareness and practice of many of the aspects of pharmacovigilance (especially that medicinal

8 products could cause undesired effects) had existed for hundreds of years, being first formally discussed in the 1700s. The term "pharmacovigilance" was coined in France, and the concept

10 was first formally used in the French open literature during 1974-1976 (e.g., see: ${ }^{[35-38]}$ largely prompted by the 1961 thalidomide-phocomelia affair, which catalyzed expanded

12 monitoring of ADRs (e.g., Hurwitz and Wade ${ }^{[39]}$ ). This, in turn, led to the formation of the French Association of Regional Centers PharmacoVigilance (Centres Régionaux de

14 PharmacoVigilance). "Pharmacovigilance" entered the English literature in the 1980s (e.g., Moore et al. $\left.{ }^{[40]}\right)$. An historical perspective is provided by van Grootheest. ${ }^{[41]}$ With a look to the

16 future, the US FDA has launched an effort (the Sentinel Initiative) to develop a national computer network capable of mining postmarket surveillance databases for drug safety problems 18 (the Sentinel System). ${ }^{[42]}$

20 Only in the last 2 years has a realization emerged for the analogous need to pay attention to APIs that enter the environment as pollutants. This has prompted the coining of a number of

22 expressions that deal with the interactions (and possible adverse effects) of API residues with the environment and the possible stewardship approaches for lessening these impacts. These terms 
first appeared in the open literature in 2006-2007 and include: Environmental Pharmacology, ${ }^{[43]}$

2 Ecopharmacology, ${ }^{[44]}$ Ecopharmacovigilance, ${ }^{[45]}$ and Pharmacoenvironmentology. ${ }^{[43,46]}$

4 Integrating all of these terms and approaches under one conceptual framework could be a significant step forward in fostering a stronger understanding of the intimate linkage between

6 human and ecological health. In this paper, we propose a framework termed "pharmEcovigilance" (Figure 2), which would merge traditional pharmacovigilance with

8 ecopharmacovigilance - encompassing the many dimensions of both ecological and human health. PharmEcovigilance would emphasize the fact that human and ecological health are

10 intimately connected, and that actions designed to protect one could afford improvements to the other. PharmEcovigilance would seek to optimize the effectiveness and overall safety of the

12 lifecycle of medications, which includes design, manufacturing, sales/distribution, prescribing/dispensing, and usage. This could be accomplished largely by: emphasizing the

14 imperative to prescribe only the most effective medications in efficacious minimal doses individualized for each patient; dispensing in quantities and for durations that ensure patient

16 compliance (full consumption); and minimizing/eliminating the generation of leftover medications — so the need for disposal is actively avoided. The major objectives of

18 pharmEcovigilance would be to: minimize impacts on the environment from APIs as pollutants; minimize exposure of humans via consumption of APIs "recycled" from the environment (e.g., 20 as trace residues in drinking waters and foods); and minimize the hazards posed to safety and health from diversion or scavenging of unused medications by humans, pets, and wildlife from 22 homes, trash, and other locations. ${ }^{[2]}$ 
That APIs are ubiquitous in the environment makes obvious the connection that should exist

2 between the practice of medicine and the study and protection of the environment. The two are intimately tied but little recognized as such. The two share many commonalities and connections.

4 Just consider the processes of data collection, epidemiology, diagnosis, mitigation/treatment, prognosis, determination of vulnerability, and pollution/disease prevention. Each of these plays a

6 critical role in both health care and in environmental protection - in the ecology of health and in the health of ecology. Improvements in one can leverage unintended improvements in the other.

8

\section{Potential Consequences of Ecological Exposure to APIs}

10 Two types of ecological exposures to APIs occur. The first is a general, primary route that results in chronic, low-level exposures of the aquatic environment from the on-going release of APIs via

12 sewage and trash. The second results in acute poisonings made possible by unique, unforeseen circumstances, such as improper disposal of highly medicated animal carcasses (see example in

14 Table I) or of unsecured medications in trash (see Figure 1).

16 For the aquatic environment, major unknowns include the consequences of chronic (sometimes transgenerational) exposure to very low levels of multiple pharmaceutical residues. This

18 exposure sometimes involves receptors that differ from those in humans, and mechanisms of action can change as the exposure levels are reduced (known as mixed-mode dose-response).

20 The potential for adverse or off-target effects can increase when multiple APIs with the same mechanism of action occur together. Two examples are selective serotonin reuptake inhibitors

22 (SSRIs), such as fluoxetine, and efflux pump inhibitors, ${ }^{[4]}$ such as reserpine; simultaneous exposure to multiple APIs among a particular class can result in concentration (or dose) addition, 
effectively serving to increase the actual dose or level of exposure. The behavioral responses in

2 fin- and shell-fish from exposure to SSRIs at ppb $(\mu \mathrm{g} / \mathrm{L})$ levels are one example. ${ }^{[47]}$

4 More pronounced effects can occur when very potent APIs are released in sewage. ${ }^{[48]}$ A prime example occurs with $17 \alpha$-ethynylestradiol, prescribed for oral contraception, to which fish are

6 sensitive at the ppt (ng/L) level; a recent experiment in a Canadian test lake has shown the complete collapse of a fish population after one year of exposure at 5 ppt. ${ }^{[49]}$ Some APIs can act

8 as indirect toxicants. A prime example is those APIs that can inhibit efflux pumps (verapamil is an example), which serve as a first line of defense against toxic substances for many aquatic

10 organisms. Inhibition of efflux pumps can greatly increase intracellular exposure to levels of chemical toxicants that a organism could ordinarily sustain. ${ }^{[50]}$

\section{Concerns Regarding Human Exposure to APIs from the Environment}

14 The single most significant aspect of risk-benefit that is usually ignored in prescribing medications is that consideration is given only to the benefits that accrue to those who are willing

16 to assume the risks (such as side effects). An unknown portion of risk, however, focuses on those who are not seeking any benefits and must often assume the risks unknowingly or begrudgingly

18 as a result of surreptitious exposure. No matter how much the benefits might outweigh the risks for the consenting population, unknown risks (or at least perceived risks) also can accrue to those

20 who are unaware and to vulnerable populations, such as older adult and fetal populations.

22 Exposure for humans to environmental residues of APIs, compared with aquatic exposure, is probably lower because feral residues occur in drinking water at greatly reduced levels; but foods 
grown on sewage- or manure-amended acreage may contain substantially higher

2 concentrations. ${ }^{[22]}$ Another major difference is that ecological exposure is considered adverse only when the effects are expressed at the level of an entire population (e.g., failure of

4 reproductive sustainability). For humans, in contrast, any type of effect on an individual could be considered adverse if the exposure were unwarranted and not welcome. Even psychological

6 effects (e.g., from the nocebo phenomenon) could result if a consumer became overly concerned by the presence of minute residues of APIs in their drinking water. ${ }^{[3]}$

Additional unknowns arise regarding human exposure. These are summarized in Table III. Some

10 of the currently unanswerable questions include: How does one assess the significance of exposure due to: (i) chronic exposures to APIs designed for short-term use; (ii) exposure routes

12 that differ from the approved clinical routes (e.g., ingestion of APIs that are approved for dermal use only); (iii) simultaneous exposure to low-levels of multiple APIs, especially those that are

14 contraindicated (this could be particularly problematic for APIs present below purported noeffects levels but which share common modes of action, making the effective dose the sum of the 16 individual doses); and (iv) unintended, unexpected exposure of certain sub-populations to APIs that should be actively avoided (e.g., drugs contraindicated during pregnancy; chemotherapeutics 18 or antipsychotics for healthy people)?

20 While no adverse effects from human exposure to minute levels of APIs in drinking water have been documented, ${ }^{[19]}$ concern persists nonetheless, primarily because of the difficulty in ruling

22 out the possibility of effects, especially those that might be subtle (behavioral or learning impairment) or delayed in onset, especially with regard to fetal exposure. ${ }^{[52,53]}$ Certain APIs have 
the potential to elicit effects at concentrations similar to those found in the environment. One

2 example is ethynylestradiol ${ }^{[49]}$ and another is morphine, which can achieve analgesia in rats at extremely low doses; the simultaneous administration to rats of $0.1 \mu \mathrm{g} / \mathrm{kg}$ morphine coupled with

$4 \quad 1 \mathrm{pg} / \mathrm{kg}$ naltrexone (an opioid receptor antagonist) can achieve the same level of analgesia as with morphine alone at the conventional dosage of about $1-10 \mathrm{mg} / \mathrm{kg}$ - a dosage about six 6 orders of magnitude higher. ${ }^{[27]}$

\section{Role of the Physician and other Prescribers}

Some of the many pharmEcovigilance actions that could be implemented by the medical

10 community are summarized in Table IV. A wide spectrum of pharmEcovigilance programs could be designed to reduce the occurrence and accumulation of leftover drugs, thereby reducing the

12 need for disposal, reducing the risks of drug diversion, improving patient outcomes, and conserving healthcare resources. Some approaches are particularly intriguing because they can

14 be implemented within a physician's office simply with improved vigilance.

16 It is clear that a large, diverse array of data can be mined from tracking the leftover, unused, unwanted drugs from patients. ${ }^{[23,2]}$. These data can then be used to design a variety of measures to

18 reduce drug wastage. Time considerations aside, by collecting drug wastage data from patients, a wide spectrum of weaknesses and liabilities associated with the administration of healthcare

20 could possibly be quickly revealed and perhaps actions devised for improvement.

22 Such information collected by physicians could help to identify those patients who are noncompliant with their treatment regimens. Non-compliance continues to be a major public health 
concern, and any measure to improve compliance holds the potential to also improve therapeutic

2 outcomes. ${ }^{[4,5]}$ In addition, the information would help to discover trends in pharmaceuticals most commonly discarded by patients. Armed with these data, physicians could further evaluate the

4 choice of treatment for a particular patient. Another opportunity in the course of regular medical practice is those scenarios where a chosen medication is either discontinued or changed by the

6 physician. At these management junctures, the physician could question the patient regarding quantities of original drugs remaining and further instruct the patient on proper methods of

8 disposal.

10 Medical management has increasingly emphasized the importance of proper nutrition and lifestyle choices as part of disease treatment and preventative care. Reducing the introduction of

12 pharmaceuticals into the environment, and thereby minimizing the exposure and potential risks to human health, is another important reason why this trend should continue. Certainly,

14 pharmaceuticals have the potential to alleviate symptoms, cure disease, and improve the overall quality of life for many patients. However, it would be prudent if healthcare professionals would

16 continue to try to prevent disease and improve wellness by coaching, teaching and encouraging healthy lifestyles. This may perhaps reduce reliance on medications, avoiding the effects of

18 chronic administration of prescribed drugs and reducing our negative impact on our environment and ecological habitat. This, in turn, might abate the concern for human exposure to "recycled"

20 pharmaceutical residues. 


\section{CONCLUSION}

2 The impacts of medical practice have been shown to extend far beyond humans in their immediate roles as patients. For this reason, the relationships that healthcare professionals and

4 patients have with medications might also include consideration of pharmEcovigilance. Like any profession that deals with chemicals, perhaps a major challenge to be faced is how to ensure the

6 sustainability (and minimize the lifecycle exposure hazards) of a chemical-based, chemicalcentric society in the most cost-effective and safest manner. Given that the medical community is

8 a major source of numerous "exotic" chemical pollutants in the environment (with thousands of chemically distinct APIs in current use) — albeit at very low levels — an imperative could be

10 created for designing and implementing approaches for reducing and controlling this source of pollution. With reduced wastage of medications, in part driven by appropriate or rational

12 prescribing and dispensing, ${ }^{[54,55]}$ the ecological footprint of medicine could be greatly reduced, with concomitant improvements in many aspects of healthcare. The collateral benefits from

14 reduced wastage would include continual progress toward the optimization of delivery, effectiveness, and cost of healthcare, as well as improved safety for humans, pets, and wildlife, 16 resulting from reduced diversion and scavenging of leftover medications. 


\section{REFERENCES}

1. Oaks JL, Gilbert M, Virani MZ, et al. Diclofenac residues as the cause of vulture population decline in Pakistan. Nature 2004; 427(6975): 630-633

2. Ruhoy IS, Daughton CG. Beyond the Medicine Cabinet: An Analysis of Where and Why Medications Accumulate. Environ Internat. In press; doi:10.1016/j.envint.2008.05.002

3. Daughton CG. Groundwater recharge and chemical contaminants: Challenges in communicating the connections and collisions of two disparate worlds. Ground Water Monitor Remediation 2004; 24(2): 127-138

4. Bosworth HB, Oddone EZ, Weinberger M, editors. Patient Treatment Adherence: Concepts, Interventions, and Measurement. Routledge, Taylor \& Francis Group, 2006

5. O'Donohue WT, Levensky ER, editors. Promoting Treatment Adherence: A Practical Handbook for Health Care Providers. Sage Publications, Inc.: New York, 2006

6. Teske J, Weller JP, Larsch K, et al. Fatal outcome in a child after ingestion of a transdermal fentanyl patch. Int J Legal Med 2007; 121(2): 147-151

7. Flannagan LM, Butts JD, Anderson WH. Fentanyl patches left on dead bodies -- potential source of drug for abusers. J Forensic Sci 1996; 41(2): 320-321 
8. U.S. EPA. U.S. Environmental Protection Agency. Pharmaceuticals and Personal Care Products (PPCPs): Relevant Literature [online]. Available from URL: http://www.epa.gov/ppcp/lit.html [Accessed 2007 December 29].

4

9. Kümmerer KE, editor. Pharmaceuticals in the Environment: Sources, Fate, Effects, and Risk. 2nd ed. Springer: Berlin Heidelberg, 2004

10. Petrovic M, Barcelo D, editors. Analysis, Fate, and Removal of Pharmaceuticals in the Water Cycle. Wilson \& Wilson's Comprehensive Analytical Chemistry Series (D. Barcelo, editor), Elsevier, 2007

12 11. Marquardt KA, Tharratt RS, Musallam NA. Fentanyl remaining in a transdermal system following three days of continuous use. Ann Pharmacother 1995; 29(10): 969-71

12. Barnes AJ, Smith ML, Kacinko SL, et al. Excretion of Methamphetamine and Amphetamine in Human Sweat Following Controlled Oral Methamphetamine Administration. Clinical Chem 2008; 54: 172-180

13. Høiby N, Pers C, Johansen HK, et al. Excretion of ß-Lactam Antibiotics in Sweat—a Neglected Mechanism for Development of Antibiotic Resistance? Antimicrob Agents Chemother 2000 October; 44(10): 2855-2857 
14. Cunningham VL, Buzby M, Hutchinson T, et al. Effects of Human Pharmaceuticals on Aquatic Life: Next Steps. Environ Sci Technol 2006; 40(11): 3456-3462

15. Joss, A, Zabczynski S, Gobel A, et al. Biological degradation of pharmaceuticals in municipal wastewater treatment: Proposing a classification scheme. Water Res 2006 May; 40(8): 1686-1696

16. Ruhoy IS, Daughton CG. Types and quantities of leftover drugs entering the environment via disposal to sewage - revealed by coroner records. Sci Total Environ 2007; 388(1-3): 137-148

17. Daughton CG. Environmental stewardship and drugs as pollutants. Lancet 2002; 360: $1035-1036$

18. NSFC. National Small Flows Clearinghouse, National Environmental Services Center. West Virginia University. Septic System Information [online]. Available from URL: http://www.nesc.wvu.edu/NSFC/nsfe_septicnews.html. [Accessed 2007 December 29].

19. Daughton CG. Pharmaceuticals as environmental pollutants: The ramifications for human exposure. In: International Encyclopedia of Public Health. (Kris Heggenhougen and Stella Quah, Editor-in-Chief), Elsevier, Academic Press. In press 
20. US Senate. U.S Senate Committee on Environment \& Public Works (Subcommittee on Transportation Safety, Infrastructure Security, and Water Quality), 15 April 2008, hearing on "Pharmaceuticals in the Nation's Water: Assessing Potential Risks and Actions to Address the Issue" [online]. Available from URL: http://epw.senate.gov/public/index.cfm?FuseAction=Hearings.Hearing\&Hearing_ID=306 41a14-802a-23ad-4b51-a10dd439793f

21. Jones-Lepp TL, Stevens R. Pharmaceuticals and personal care products in biosolids/sewage sludge: the interface between analytical chemistry and regulation. Anal Bioanal Chem 2007; 387: 1173-1183

22. Boxall ABA, Johnson P, Smith EJ. et al Uptake of veterinary medicines from soils into plants. J Agric Food Chem 2006, 54 (6): 2288-2297

23. Daughton CG and Ruhoy IS. Accumulation and disposal of leftover medications: A key aspect of pharmEcovigilance. In: An Introduction to Environmental Pharmacology (ISBN \# 978-81-906070-5-6). (SZ Rahman and V Gupta, Editors), Ibn Sina Academy, Aligarh, India. In press

24. ONDCP . Office of National Drug Control Policy Washington, DC. Proper Disposal of Prescription Drugs: Federal Guidelines [online]. 2007. Available from URL: http://www.whitehousedrugpolicy.gov/drugfact/factsht/proper_disposal.html [Accessed 2007 December 29]. 
25. Glassmeyer ST, Hinchey EK, Boehme SE, et al. Disposal Practices for Unwanted Residential Medications in the United States. Environ Internat. In press

26. EU. Directive 2004/27/EC of the European Parliament and of the Council of 31 March 2004 amending Directive 2001/83/EC on the Community code relating to medicinal products for human use. Official Journal of the European Union, 30.04.2004 P, L 136/37. Available from URL: http://efcg.cefic.org/isoFILES/publications/items/DOWNLOAD_73.pdf [Accessed 2008 June 4]

27. Daughton CG. Cradle-to-cradle stewardship of drugs for minimizing their environmental disposition while promoting human health. I. Rationale for and avenues toward a green pharmacy. Environ Health Perspect 2003; 111(5): 757-774

28. Daughton CG. Cradle-to-cradle stewardship of drugs for minimizing their environmental disposition while promoting human health. II. Drug disposal, waste reduction, and future direction. Environ Health Perspect 2003; 111(5): 775-785

29. Kummerer K. Sustainable from the very beginning: rational design of molecules by life cycle engineering as an important approach for green pharmacy and green chemistry. Green Chem 2007; 9(8): 899-907 
30. Khetan SK, Collins TJ. Human pharmaceuticals in the aquatic environment: a challenge to green chemistry. Chem Rev 2007; 107(6): 2319-2364

31. Daughton CG and Ruhoy IS. PharmEcovigilance: Aligning pharmacovigilance with environmental protection. In: An Introduction to Environmental Pharmacology (ISBN \# 978-81-906070-5-6). (SZ Rahman and V Gupta, Editors), Ibn Sina Academy, Aligarh, India. In press

6

32. Enick OV, Moore MM. Assessing the assessments: Pharmaceuticals in the environment. Environ Impact Assessment Rev 2007; 27(8): 707-729

33. Aronson JK, editor. Meyler's Side Effects of Drugs: The International Encyclopedia of Adverse Drug Reactions and Interactions. 15th rev. ed. Elsevier Science, 2006

34. WHO. World Health Organization. WHO Policy Perspectives on Medicines, No. 09, October 2004 - Pharmacovigilance: Ensuring the Safe Use of Medicines [online]. Available from URL: http://www.who.int/medicinedocs/collect/medicinedocs/pdf/s6164e/s6164e.pdf [Accessed 2008 April 18].

35. Dunlop D. Pharmacovigilance in the framework of recording and control of drugs in the United Kingdom [in French]. Therapie 1974 Nov-Dec; 29(6): 799-804 
36. Efthymiou ML. Bibliography in pharmacovigilance [in French]. Eur J Toxicol Environ Hyg 1975 Sep-Oct; 8(5): 319-20

37. Evreux JC, Lagier G. The efficacy of pharmacovigilance--principles and proposals [in French]. Therapie 1976 Sep-Oct; 31(5): 581-6

6

38. Lagier G, Efthymiou ML, Lechat P, et al. Pharmacovigilance in the hospital. First results [in French]. Therapie 1974 Nov-Dec; 29(6): 805-10

39. Hurwitz N, Wade OL. Intensive Hospital Monitoring of Adverse Reactions to Drugs. Br Med J 1969; 1(5643): 531-536

40. Moore N, Paux G, Begaud B, et al. Adverse Drug Reaction Monitoring: Doing it the French Way. The Lancet 1985; 326(8463): 1056-1058

41. van Grootheest K. The Dawn of Pharmacovigilance: An Historical Perspective. Internat J Pharmaceut Med 2003; 17(5-6): 195-200

18

42. FDA. FDA's Sentinel Initiative. U.S. Food and Drug Administration, 22 May 2008. Available: http://www.fda.gov/oc/initiatives/advance/sentinel/ [Accessed 2008 June 4]

20 43. Rahman SZ, Khan RA. Environmental pharmacology - a new discipline. Indian J Pharmacol 2006 Aug; 38 (4): 229-230 
44. Kummerer K, Velo G. Ecopharmacology: A New Topic of Importance in Pharmacovigilance. Drug Safety 2006; 29 (5): 371-373

45. Keck G. Teaching environmental toxicology for veterinary students and veterinarians: some new trends. J Vet Pharmacol Therap 2006; 29(suppl 1): 15-16

46. Rahman SZ, Khan RA, Gupta V, et al. Pharmacoenvironmentology - a component of pharmacovigilance. Environ Health 2007, 6:20: E1-3

47. Daughton CG, Ternes TA. Pharmaceuticals and personal care products in the environment: Agents of subtle change? Environ Health Perspect 1999; 107 (suppl 6): $907-938$

48. Ankley GT, Brooks BW, Huggett DB, et al. Repeating History: Pharmaceuticals in the Environment. Environ Sci Technol 2007; 41(24): 8211-8217

49. Kidd KA, Blanchfield PJ, Mills KH, et al. Collapse of a fish population after exposure to a synthetic estrogen. Proc Nat Acad Sci 2007; 104(21): 8897-8901

50. Daughton CG. Pharmaceuticals in the environment: Overarching issues and overview. In: Daughton CG , Jones-Lepp T, editors. Pharmaceuticals and Personal Care Products in the Environment: Scientific and Regulatory Issues. Symposium Series 791; American Chemical Society: Washington, D.C., 2001: 2-38. Available from URL: 
http://www.epa.gov/nerlesd1/bios/daughton/book-summary.htm. [Accessed 2008

February 13].

51. Grandjean P, Bellinger D, Bergman A, et al. The Faroes statement: Human health effects of developmental exposure to chemicals in our environment. Basic Clinical Pharmacol Toxicol 2007; 102: 73-75.

52. Collier AC. Pharmaceutical Contaminants in Potable Water: Concerns for Pregnant Women and Children. EcoHealth J 2007; 4(2): 164-171

53. Kuehn BM. Traces of drugs found in drinking water: Health effects unknown, safer disposal urged. J Am Med Assoc 2008; 299(17): 2011-2013

54. Pollock M, Bazaldua OV, Dobbie AE. Appropriate prescribing of medications: an eightstep approach. Am Fam Physician 2007; 75(2): 231-6

55. Crigger N. Improving Nurse Practitioner Practice through Rational Prescribing. J Nurse Practitioners 2008; 4(2): 120-5

56. The Cochrane Collaboration. The Cochrane Library [online]. Available from URL: http://www.cochrane.org/reviews/clibintro.htm [Accessed 2008 February 13]. 
57. U.S. FDA. U.S. Food and Drug Administration. Good Reprint Practices for the Distribution of Medical Journal Articles and Medical or Scientific Reference Publications on Unapproved New Uses of Approved Drugs and Approved or Cleared Medical Devices [online]. 2007. Available from URL: http://oversight.house.gov/documents/20071130103225.pdf. [Accessed 2008 February $14]$.

58. Stockholm City Council. Environmentally Classified Pharmaceuticals. January 2008 edition. Available from URL: http://www.janusinfo.se/imcms/servlet/GetDoc?meta_id=10205; via www.janusinfo.se/environment [Accessed 2008 April 20]

59. Sherman R, Hickner J. Academic physicians use placebos in clinical practice and believe in the mind-body connection. J Gen Intern Med 2008; 23(1): 7-10

16 60. U.S. FDA. U.S. Food and Drug Administration. Food and Drug Administration Amendments Act of 2007. H. R. 3580 [online]. 2007. Available from URL: http://www.fda.gov/oc/initiatives/advance/fdaaa.html\#law. [Accessed 2007 December 29].

61. Doerr-MacEwen N, Haight M. Expert Stakeholders' Views on the Management of Human Pharmaceuticals in the Environment. Environ Management 2006; 38(5): 853-866 
62. CFR. Title 21--Food and Drugs, Chapter I--food and Drug Administration, Department of Health and Human Services, Subchapter C-Drugs: General, Part 203-Prescription Drug Marketing, Subpart D—Samples, § 203.39 Donation of drug samples to charitable institutions [online]. Available from URL: $\underline{\text { http://ecfr.gpoaccess.gov/cgi/t/text/text- }}$ $\underline{\mathrm{idx}} ? \mathrm{c}=\mathrm{ecfr} \& \mathrm{sid}=\mathrm{ec} 1033 \mathrm{dbd} 03546 \mathrm{f} 7 \mathrm{dc} 73 \mathrm{a} 2 \mathrm{~d} 35 \mathrm{c} 683 \mathrm{a} 6 \mathrm{c} \& \mathrm{rgn}=\mathrm{div} 8 \& \mathrm{view}=$ text $\&$ node $=21$ :4.0.1.1.4.4.1.10\&idno=21 [Accessed 2008 April 20]

63. WHO. Guidelines for the Safe Disposal of Unwanted Pharmaceuticals in and after Emergencies: Interagency Guidelines, World Health Organization, WHO/EDM/PAR/99.2, 1999, 31pp. [Accessed 2008 June 4]Available: http://www.who.int/water_sanitation_health/medicalwaste/unwantpharm.pdf

64. NCSL. National Conference of State Legislatures. 2008 Prescription Drug State Legislation [online]. Available from URL: http://www.ncsl.org/programs/health/drugbill08.htm [Accessed 2008 April 20]

65. New York State. Title 27 Drug Management and Disposal. A00840: An ACT to amend the environmental conservation law, in relation to the management and disposal of drugs [online]. Available: http://assembly.state.ny.us/leg/?bn=A00840\&sh=t [Accessed 2008 April 20]

22 66. McKee G. Keeping drugs out of the toilet: the need for federal action to allow consumer drug donation. 10 Quinnipiac Health L J 2006; 45-76 
Table I. Medications Have Lives Extending Beyond the Patient

\begin{tabular}{l|l}
\hline $\begin{array}{l}\text { Consequence of APIs } \\
\text { in the Environment }\end{array}$ & \multicolumn{1}{c}{ Example of Consequence } \\
\hline $\begin{array}{l}\text { Contamination of the } \\
\text { environment }\end{array}$ & $\begin{array}{l}\text { Continual, low-level exposure of aquatic organisms to APIs excreted } \\
\text { or washed from the skin, or disposed via sewerage. }\end{array}$ \\
\hline Acute risks for wildlife & $\begin{array}{l}\text { Acute poisoning can occur (especially raptors and scavengers) when } \\
\text { medicated or euthanized animal carcasses are improperly disposed } \\
\text { (e.g., extirpation of vultures in Asia from scavenging the carcasses } \\
\text { of cattle that have been treated with diclofenac }{ }^{[1]} \text { ). }\end{array}$ \\
\hline $\begin{array}{l}\text { Widespread, } \\
\text { unintended exposure of } \\
\text { the general public to } \\
\text { "recycled" APIs }\end{array}$ & $\begin{array}{l}\text { The routine use of medications poses unknown risks for the general } \\
\text { public by chronic ingestion of drinking water and foods tainted with } \\
\text { minute residues of APIs recycled from the environment. }\end{array}$ \\
\hline $\begin{array}{l}\text { Diversion of unused, } \\
\text { unwanted drugs; } \\
\text { exacerbated need for } \\
\text { disposal }\end{array}$ & $\begin{array}{l}\text { Leftover medications accumulate at a wide spectrum of locations in } \\
\text { society, }{ }^{[2]} \text { eventually leading to the need for disposal and increased } \\
\text { likelihood of diversion and accidental poisonings. }\end{array}$ \\
\hline $\begin{array}{l}\text { Contamination of } \\
\text { drinking water }\end{array}$ & $\begin{array}{l}\text { Can lead to consumer distrust in municipal water supplies and } \\
\text { catalyze public rejection of water recycling programs; could also } \\
\text { elicit the nocebo effect. }\end{array}$ \\
\hline $\begin{array}{l}\text { Disposal poses some } \\
\text { unique environmental } \\
\text { hazards }\end{array}$ & $\begin{array}{l}\text { Disposal of unwanted medications to sewers can result in transient } \\
\text { concentrations much higher than those resulting from ongoing } \\
\text { excretion. }\end{array}$ \\
\hline $\begin{array}{l}\text { Development of } \\
\text { antibiotic resistance }\end{array}$ & $\begin{array}{l}\text { Minute concentrations of antibiotic residues in the environment } \\
\text { from excretion are probably too low to promote bacterial resistance. } \\
\text { But episodic, transiently high concentrations from disposal might } \\
\text { have an effect within sewer lines; the higher levels in sewage sludge } \\
\text { could also possibly promote resistance. }\end{array}$ \\
\hline
\end{tabular}


Table II. Medical and Environmental Consequences of Accumulated, Leftover Medications

\begin{tabular}{l|l}
\hline $\begin{array}{c}\text { Consequence of } \\
\text { Leftover Medications }\end{array}$ & \multicolumn{1}{c}{ Example of Consequence } \\
\hline $\begin{array}{l}\text { Wasted healthcare } \\
\text { resources }\end{array}$ & $\begin{array}{l}\text { Leftover, unused drugs range from inexpensive OTC bulk drugs to } \\
\text { costly prescription medications; leftover drugs can be indicative } \\
\text { they were unneeded or ineffective. }\end{array}$ \\
\hline $\begin{array}{l}\text { Lost opportunities to } \\
\text { treat }\end{array}$ & $\begin{array}{l}\text { Unused medications can mean the patient imprudently terminated } \\
\text { therapy prematurely, for any number of reasons (e.g., Bosworth et } \\
\text { al. }{ }^{[4]} \text { O'Donohue and Levensky). }{ }^{[5]}\end{array}$ \\
\hline Risky self-medication & $\begin{array}{l}\text { Diverted medications can be used by others attempting to self- } \\
\text { medicate. }\end{array}$ \\
\hline $\begin{array}{l}\text { Unintentional } \\
\text { poisonings }\end{array}$ & $\begin{array}{l}\text { Access to leftover medications (or partially used medical devices } \\
\text { such as transdermal patches) by children (e.g., Teske et al. } \\
\text { adults, }) \text { other } \\
\text { disposal into or wildlife through accidental spillage or imprudent }\end{array}$ \\
\hline Facilitates diversion & $\begin{array}{l}\text { Access by those for whom the medication was not intended } \\
\text { promotes abuse and sustains addiction; even used medicated patches } \\
\text { (e.g., fentanyl) can be abused (e.g., Flannagan et al. }{ }^{\left[{ }^{\prime}\right]} \text { ). }\end{array}$ \\
\hline $\begin{array}{l}\text { Imprudent disposal } \\
\text { contaminates the } \\
\text { environment }\end{array}$ & $\begin{array}{l}\text { Disposal to sewerage leads to continual introduction of APIs to } \\
\text { surface or ground waters, as well as to land (via sewage sludge); } \\
\text { disposal to trash promotes accumulation in landfills. }\end{array}$ \\
\hline
\end{tabular}


Table III. Significance of Exposure of the General Public to Ambient APIs (via recycling in drinking water and food)

\begin{tabular}{|c|c|}
\hline Exposure Factor & Significance \\
\hline Dosage is uncontrolled & $\begin{array}{l}\text { APIs in drinking water and foods occur at arbitrary, } \\
\text { unpredictable concentrations, generally less than } 10 \mathrm{ng} / \mathrm{L} \text {; } \\
\text { exposure can occur on a chronic, indefinite basis. }\end{array}$ \\
\hline $\begin{array}{l}\text { Route of exposure may not } \\
\text { be approved or studied }\end{array}$ & $\begin{array}{l}\text { Exposure routes may differ from approved routes of } \\
\text { administration (e.g., ingestion of APIs approved only for } \\
\text { topical use). }\end{array}$ \\
\hline $\begin{array}{l}\text { API may not be approved for } \\
\text { the exposed person }\end{array}$ & $\begin{array}{l}\text { Many APIs are not approved for certain segments of the } \\
\text { population (e.g., infants, pregnant women, elderly, immune- } \\
\text { compromised, particular gender, etc.) who should actively } \\
\text { avoid exposure. One example is drugs contraindicated during } \\
\text { pregnancy. }\end{array}$ \\
\hline $\begin{array}{l}\text { Exposure is unanticipated by } \\
\text { the exposed person }\end{array}$ & $\begin{array}{l}\text { Exposure via drinking water and foods, no matter how low the } \\
\text { level, is an event not expected or recognized as normal by the } \\
\text { public. }\end{array}$ \\
\hline $\begin{array}{l}\text { Dose is not consented to by } \\
\text { the exposed person }\end{array}$ & $\begin{array}{l}\text { Exposure via API-contaminated drinking water and foods } \\
\text { occurs without the knowledge of the consumer. }\end{array}$ \\
\hline $\begin{array}{l}\text { Exposed person has no } \\
\text { opportunity to refuse the } \\
\text { dose }\end{array}$ & $\begin{array}{l}\text { Even if the consumer knew that drinking water and foods were } \\
\text { routinely contaminated, alternatives may not be available. }\end{array}$ \\
\hline $\begin{array}{l}\text { Exposure duration can be } \\
\text { chronic and indefinite }\end{array}$ & $\begin{array}{l}\text { With the continual release of APIs via sewage, ambient } \\
\text { environmental residues can persist, and trace contamination of } \\
\text { drinking water and foods will sustain. Unlike long-term } \\
\text { maintenance drugs, certain medications are intended for use } \\
\text { over much shorter periods of time. }\end{array}$ \\
\hline Simultaneous exposure & $\begin{array}{l}\text { Exposure to low-levels of multiple APIs could be particularly } \\
\text { problematic for APIs that are contraindicated (resulting in } \\
\text { adverse interactions) or that share common modes of action } \\
\text { (yielding a larger, combined dose). }\end{array}$ \\
\hline $\begin{array}{l}\text { Potential effects are } \\
\text { unknown and not being } \\
\text { monitored for }\end{array}$ & $\begin{array}{l}\text { Human effects are unknown for doses that amount to at most } \\
\text { micrograms per day. The possibility of subtle effects (e.g., } \\
\text { behavioral or learning disorders, or delayed-onset effects) has } \\
\text { never been examined. Another unexplored issue is that of } \\
\text { allergic or auto-immune response. }\end{array}$ \\
\hline $\begin{array}{l}\text { Nocebo effect can be } \\
\text { provoked }\end{array}$ & $\begin{array}{l}\text { The nocebo effect entails an adverse response from exposure } \\
\text { (or even anticipated exposure) to substances at non-hazardous } \\
\text { levels. Unwarranted perceived risk and the nocebo effect can } \\
\text { jeopardize the implementation of water recycling programs. }\end{array}$ \\
\hline
\end{tabular}

${ }^{\mathrm{a}}$ Footnote.

This concern has been codified in the "Faroes Statement" on "Human health effects of developmental exposure to environmental toxicants", ${ }^{51]}$ which emphasizes that beyond the traditional view of toxicity — where the "dose makes the poison" — exists a second dimension, where the "timing makes the poison." 
Table IV. Actions to Reduce APIs in the Environment and Protect Human Health and Safety

\begin{tabular}{|c|c|}
\hline $\begin{array}{l}\text { Pollution Reduction } \\
\text { Action }\end{array}$ & Example or Benefit \\
\hline $\begin{array}{l}\text { Reduce patient non- } \\
\text { compliance }\end{array}$ & $\begin{array}{l}\text { Implement approaches for gauging the magnitude and extent of } \\
\text { patient non-compliance and for its reduction. }{ }^{[2]} \text { Non- } \\
\text { compliance can promote disposal of leftovers, bypassing the } \\
\text { extensive metabolism that can occur for some APIs. }\end{array}$ \\
\hline $\begin{array}{l}\text { Rational or appropriate } \\
\text { prescribing }\end{array}$ & $\begin{array}{l}\text { Follow evidence-based prescribing, especially for antibiotics } \\
\text { (e.g., see: the Cochrane Collaboration }{ }^{[56]} \text { ); be alert to off-label } \\
\text { uses, especially for children. Evaluate unapproved new uses } \\
\text { purported to be effective for approved drugs. }{ }^{[57]} \text { Inform patients } \\
\text { of a prospective medication's NNT (number needed to treat). } \\
\text { Consider the classification system developed in Sweden for } \\
\text { assessing the potential for impact of an API on the } \\
\text { environment. }\end{array}$ \\
\hline $\begin{array}{l}\text { Prescribe medications with } \\
\text { optically pure APIs }\end{array}$ & $\begin{array}{l}\text { Chiral drugs cut by at least half the quantity of API needed for } \\
\text { therapeutic doses (depending on how many therapeutically } \\
\text { active optical isomers compose a racemic drug); for example, } \\
\text { albuterol is a racemic drug having two optical isomers, only } \\
\text { one of which is therapeutically active. }{ }^{[27]}\end{array}$ \\
\hline $\begin{array}{l}\text { Personalized medicine } \\
\text { (sometimes called "efficacy } \\
\text { pharmacogenetics") }\end{array}$ & $\begin{array}{l}\text { Genetic testing could avoid certain unnecessary, inappropriate } \\
\text { prescribing; could allow for reduction in drug dosage by } \\
\text { concentrating on those patients who should prove to be } \\
\text { responders (by identifying poor or exceptional metabolizers). }\end{array}$ \\
\hline Trial prescriptions & $\begin{array}{l}\text { 90-day courses of medications often lead to leftovers, } \\
\text { especially for drugs where patient non-compliance is high. }\end{array}$ \\
\hline Evaluate need for samples & $\begin{array}{l}\text { Samples often go unused by patients due to a lack of } \\
\text { understanding of the need or dosing, or fear of ADRs. }\end{array}$ \\
\hline $\begin{array}{l}\text { Consider prescribing } \\
\text { placebos }\end{array}$ & Placebos are widely used. ${ }^{[59]}$ \\
\hline $\begin{array}{l}\text { Increase vigilance for doctor } \\
\text { shopping }\end{array}$ & $\begin{array}{l}\text { Prevents multiple prescriptions for the same medications, or } \\
\text { different medications containing the same API. }\end{array}$ \\
\hline $\begin{array}{l}\text { Ensure patients understand } \\
\text { hidden dangers in over- } \\
\text { consuming OTC drugs }\end{array}$ & $\begin{array}{l}\text { Some drugs (e.g., acetaminophen) are inadvertently over- } \\
\text { consumed because they occur in a variety of OTC (as well as } \\
\text { prescription) drugs that are often taken together. }\end{array}$ \\
\hline $\begin{array}{l}\text { Increase vigilance for } \\
\text { polypharmacy }\end{array}$ & $\begin{array}{l}\text { Eliminating certain unneeded medications could eliminate the } \\
\text { need for others, while also reducing adverse effects. }\end{array}$ \\
\hline $\begin{array}{l}\text { Ramifications of the } \\
\text { FDAAA }\end{array}$ & $\begin{array}{l}\text { The Food and Drug Administration Amendments Act of } \\
2007^{[60]} \text { could result in reduced medication usage because of } \\
\text { provisions that: (i) expand vigilance via postmarketing studies } \\
\text { and clinical trials, (ii) expand posting of clinical trials and } \\
\text { adverse reactions for all drugs, (iii) restrictions on DTC, (iv) } \\
\text { requirements for REMS (risk evaluation mitigation strategies) } \\
\text { for certain drugs. }\end{array}$ \\
\hline
\end{tabular}




\begin{tabular}{l|l}
\hline $\begin{array}{l}\text { Provide prudent hygiene } \\
\text { instructions to patients }\end{array}$ & $\begin{array}{l}\text { Fingers or hands used to apply concentrated topical hormone } \\
\text { preparations (e.g., testosterone and estrogens) but not properly } \\
\text { washed can then transfer the API by direct contact to other } \\
\text { surfaces or people. }\end{array}$ \\
\hline $\begin{array}{l}\text { Provide clear usage } \\
\text { instructions }\end{array}$ & $\begin{array}{l}\text { For example, drugs designed for topical use are often over- } \\
\text { applied, leading to increased loadings to sewage by bathing. }\end{array}$ \\
\hline $\begin{array}{l}\text { Ensure patients understand } \\
\text { prudent disposal practices } \\
\text { for unwanted drugs }\end{array}$ & $\begin{array}{l}\text { The ONDCP issued the first U.S. federal guidance for } \\
\text { consumer disposal of unused drugs in February of } 2007 .{ }^{[24]} \text { a } \\
\text { Collection programs are another alternative. }{ }^{[61,25]}\end{array}$ \\
\hline $\begin{array}{l}\text { Ensure patients understand } \\
\text { prudent disposal practices } \\
\text { for used medical devices, } \\
\text { especially patches }\end{array}$ & $\begin{array}{l}\text { Used medical patches (especially narcotics such as fentanyl) } \\
\text { pose a major health risk for those who will reuse them or } \\
\text { accidentally come into contact with them. Current ONDCP } \\
\text { guidance }{ }^{[24]} \text { recommends flushing, but this can contaminate the } \\
\text { environment. Better disposal options might become available in } \\
\text { the future with the development of take-back programs. }\end{array}$ \\
\hline $\begin{array}{l}\text { Donate unwanted physician } \\
\text { samples to charity }\end{array}$ & $\begin{array}{l}\text { Physician samples can be donated to charitable institutions by } \\
\text { licensed practitioners if the samples meet certain criteria set } \\
\text { forth in CFR Title 21. }{ }^{[2]} \text { Some states have legislation allowing } \\
\text { closed drug-delivery systems to return certain high-cost items } \\
\text { (e.g., cancer drugs) to approved pharmacies for redispensing to } \\
\text { indigent patients. Note, however, that charitable contributions } \\
\text { during humanitarian relief efforts can pose significant } \\
\text { problems, especially for disposal of unuseable or unneeded } \\
\text { donations. }\end{array}$ \\
\hline [63]
\end{tabular}

\section{${ }^{\text {a }}$ Footnote.}

A variety of state legislation has been proposed or passed since 2006 addressing various aspects of drug reuse (such as allowing or encouraging donation of unused pharmaceutical drugs) or disposal. As of February 2008, the National Conference of State Legislatures ${ }^{[64]}$ reported that 11 more states were considering legislation addressing some aspect of reuse or recycling of pharmaceuticals. New York State A00840 ("An ACT to amend the environmental conservation law, in relation to the management and disposal of drugs" $)^{[65]}$ would prohibit "the disposal of drugs as solid waste in a landfill; requires drug manufacturers to establish drug collection programs to accept unused or expired drugs from consumers; requires consumers to return drugs to such a drug collection program; all drugs collected by a manufacturer shall be disposed of in an environmentally sound manner..." Note, however, that some non-federal laws can run crosswise of federal law, as discussed by McKee. ${ }^{[66]}$ 
Figure 1. Unintentional, Unanticipated Exposure to API Residues from the Environment SEE NEXT PAGE \{figure revised 4 June 2008 \} 


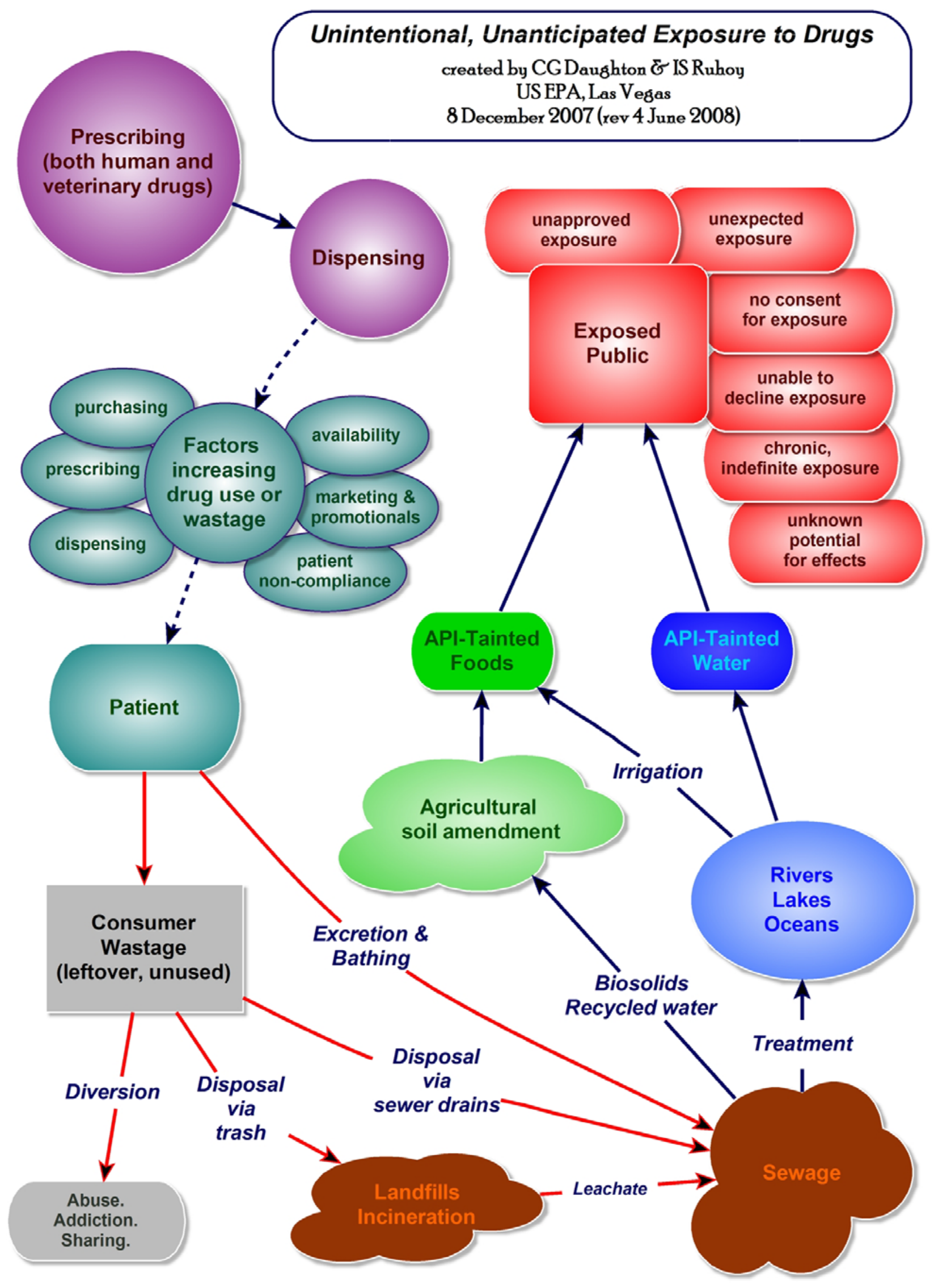

page $<41>$ of 43 
Figure 2. Role of PharmEcovigilance in Minimizing Human \& Ecological Impacts of APIs SEE NEXT PAGE 

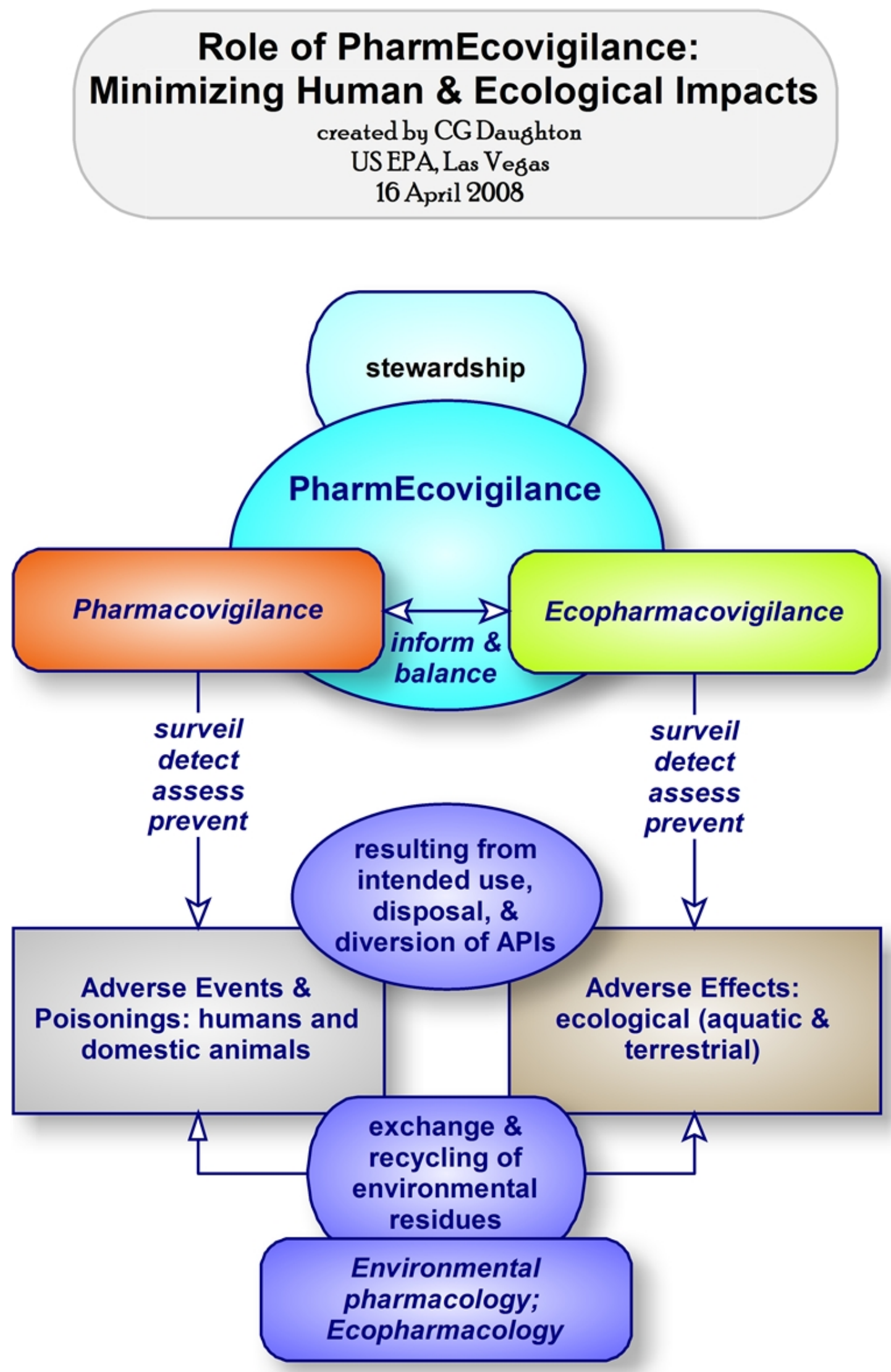